\title{
On the "Real" and "Virtual" of Cultural Tourism-— A Case Study of Yu-Qiang Culture in Beichuan County
}

\author{
Shangyun Xie \\ Sichuan University History and Culture (Tourism) College, Chengdu Sichuan, Wuhou Qu Wangjiang \\ Lu 29 HaO, 610064 \\ 66632912@qq.com
}

Keywords: Beichuan, Yu-Qiang cultural tourism, Authenticity, Virtual Reality

\begin{abstract}
Beichuan was rebuilt after the "5 1 12" earthquake , formed a number of new tourism resources and become a national 5A-level scenic spots, tourism development has new opportunities and greater space. But there are also some problems, such as tourists stay for a short time, tourism products homogenization and lack of brand culture tourism products and other issues. Beichuan tourism development should be inherited and carry forward Yu-Qiang culture as a long-term goal, not only need to consider the cultural "original real" connotation, but also through the latest technical means to construct and show the "real" Yu-Qiang culture, the use of VR technology to build brand culture Tourism products is a new way to develop self-characteristics and superior resources in Beichuan culture tourism.
\end{abstract}

\section{Introduction}

Beichuan, suffered the " 5 • 12"earthquake, was rebuilt and formed many new tourism resources, the development of tourism has a new opportunity and greater space, but also due to the earthquake caused Yu-Qiang cultural substances lack of carrier and folk art and other non-material cultural heritage crisis. Beichuan's sustainable development of tourism as well as the inheritance and protection of Yu-Qiang culture have become two important issues of concern.

At present, the study of Beichuan tourism development is mainly focused on two aspects: First, on the tourism development ideas and path of Beichuan. Some scholars put forward the leisure travel and theme forums combined development path; or proposed the earthquake site resources and Thanksgiving cultural resources combined in the development; or proposed to create a special cultural tourism town, focus on the development of leisure tourism of Qiang village. Second, the protection and development of Yu-Qiang culture. Some scholars advocate deep-seated Yu-Qiang culture, love culture and local culture, vigorously develop the cultural tourism industry; or through the creation of Qiang art boutique, to create Qiang characteristics of products and the development of Qiang tourism festival to protect and spread Yu- Qiang culture; It is believed that the advantages of Beichuan Yu-Qiang cultural resources have not been fully exploited, and we should advocated the development of Yu-Qiang culture and tourism integration.[1] The use of earthquake sites and the Yu-Qiang culture to develop the tourism industry of Beichuan is the consensus of scholars, and the specific countermeasures are similar, mostly advocated by creating Qiang village or town to develop leisure travel or through the development of Qiang cultural characteristics of tourism products or festival to highlight the Qiang culture, but it seems lack of more creative path and countermeasures. Beichuan tourism development and the protection of the Yu-Qiang culture should be promote interactive and inseparable. How to heritage and make full use of Yu-Qiang culture advantages to develop new tourism products is a new problem which worth a serious discussion of. 


\section{The Core Condition of Cultural Tourism and "Authenticity"}

The development of cultural tourism is an important way of cultural inheritance and display. Tourism activities is essentially a cultural phenomenon, and cultural tourism industry turns the precious humanistic tourism resources into consume content and to meet the tourists' demand. Therefore, we could extract two core conditions of cultural tourism development: First, the precious memories of human, that is, all kinds of historical relics; Second, consume content meet the cultural needs of tourists. The first core condition is the basic conditions, by combing the local culture and development process, which extracted the representative of cultural symbols, through the existing material and non-material historical relics to carry out systematic description and display, in order to achieve the interpretation of the local culture and reproduction. The second core condition is more complex, because different cultural groups of people on the understanding of culture and experience requirements are different. People's experience feelings exist marginal effect, the first experience have the highest level of consumption, the more the number of times, the weaker the marginal benefit. Therefore, creativity is particularly important, we need to creatively emphasis on the extraction of cultural essence and then build a cultural symbol, and promote and sell this cultural symbols to form a brand effect. For example, Guangxi's large-scale Guilin landscape real performance "impression-Liu Sanjie", which set Lijiang landscape style, Guangxi minority culture and Chinese elite artists in one, is the world's first new concept of landscape real performance. Its success lies in not only the complete extraction of the essence of national culture, but in the artistic model of the creative culture of the perfect blend of the natural landscape, coupled with the effect of celebrity and brand promotion superposition.

Cultural tourism experience not only allows tourists to enjoy the charm of culture in a relaxed environment, but the manifestations of the culture itself has become more plentiful and vivid due to the needs of the tourism market. Nevertheless, cultural tourism culture "authenticity" problem discussion is inevitable in this process. Culture and history are constructed, the so-called authenticity is subject to specific circumstances. As a descendant, we can go to explore true and false, but cannot really determine the true and false, which is the difficulty of studying the authenticity of the problem. The original culture has been with the passage of time and the iteration of the population and become elusive, blind pursuit "the original" of culture does not meet the reality, the development of things have their own laws, the power of future generations can only reproduce. For the purposes of this article, the authenticity of cultural tourism means the historical origin and development of culture, the historical relics produced in this process, and the extent to which the experience of the tourists is expected to be met.

Of course, in tourism sociology, "authenticity" is a very important concept, including the tourist attraction of the object real and the real experience of tourists. "Authenticity" reflects the objective state of culture, and the search for "real" is the motivations of tourists. Dean MacCannell said: "modern people to break their existing real life, but also to pursue and obsessed with other places 'real life'."[2] In order to better meet the curious for other culture, people tend to hold some kind of expectation to visit a representative tourist destination to make their own subjective "authenticity" judgment. As Wang Ning distinguishes the true nature of the authenticity and the authenticity of the interaction, "Real" has been changed, not only exists in the tourist object, passive waiting for tourists to observe and discover , turned to a "real" of the interaction and participation of visitors and hosts.[3] It means that the authenticity of cultural tourism have different levels. For most of the tourists, they cannot distinguish the original part of the culture from the construction part. For tourists, feel real is more important than the "original", and everything depends on whether the experience of the tourist is met or exceeded their expectations.

\section{Post-disaster Reconstruction to Form a New Cultural Tourism Resources}

Minority culture attracts countless tourists due to its unique qualities. Beichuan Qiang Autonomous County is located in the northwest of Sichuan Basin, an area of about 2867.83 square 
kilometers. Beichuan is China's only Qiang Autonomous County, Qiang population accounts for about $94.9 \%$ of the county population.

May 12, 2008, Beichuan suffered heavy losses due to the eight-level major earthquake, the county and a number of field town were razed to the ground. In the post-disaster reconstruction, Beichuan focused on the development of tourism, Mianyang municipal government, around the earthquake ruins, invested billions to built Beichuan County tourism products. After five years of reconstruction and promotion, by 2013, Beichuan has one 5A-level scenic area (Beichuan Qiangcheng tourist area), two 4A-level scenic spots (Jiuhuang mountain scenic area, Yaowang valley scenic area) and one scenic area (Xiao Zhaizigou scenic area). Beichuan Qiangcheng tourist area is the first national 5A-class tourist attractions of Mianyang city, composed of $5 \cdot 12$ Wenchuan earthquake memorial hall, Beichuan Qiang folk museum, Beichuan new county town landscape axis (Banaqia commercial street, Yu wang bridge, earthquake monument), Gina Qiang village and other attractions, with a total area of 6.01 square kilometers. September 12, 2013 officially listed operation.

\section{Current Situation and Problems of Beichuan Cultural Tourism Development}

After the "5 • 12" Wenchuan earthquake, the number of tourists fell to 200,000 people, tourism revenue fell to 139 million yuan. Through the disaster reconstruction and marketing, Beichuan county tourism began to gradually recover. Till Beichuan successful creation of national 5A-level scenic spots, the tourism industry has developed by leaps and bounds. According to Beichuan county tourism bureau's statistics, in 2013 the total number of tourists was 3.0449 million, compared with 0.56 million people in 2007 increased by 443.7\%; county tourism total income of 1.955 billion yuan, compared with 384 million yuan in 2007, an increase of $419.5 \%$. In 2016, the county received more than 5 million domestic tourism, tourism income of 4.06 billion yuan, an increase of $24.65 \%$, of which 1.77 million rural tourism reception, tourism income of 1.421 billion yuan. [4] But at the time, we also need to see that there are still some problems of the tourism industry here in Beichuan .

The first is the short time that tourists stay in Beichuan. Beichuan's traffic conditions in the reconstruction has been greatly improved, can greatly enhance the access. But on the other hand, Beichuan becomes a short-distance tourist destination, lack of overnight visitors. According to the results of author in October 2016 in Beichuan for tourists interviews and questionnaires, tourists who choose half-day tour or day trips accounted for $83.1 \%$ of the total number of tourists surveyed. Most of the self-driving tourists are basically arrive in the morning and leave in the afternoon, the tour group is basically only stay in Beichuan about half a day. This has a direct impact on the improvement of local tourism revenue.

Followed by cultural tourism products lack the core competitiveness, which is the development of cultural tourism in Beichuan where the biggest difficulties. The biggest attraction of cultural tourism is lies in unique and exclusive. After the earthquake, the original culture lost the ancient material carrier, to a certain extent, increased the difficulty of the development of cultural tourism. Beichuan in cultural tourism types and scenic development model has a greater similarity with the surrounding areas of tourism destination, because Beichuan is relocated to rebuild, so in the cultural atmosphere, the characteristics of the landscape, ethnic customs, scenic quality and other aspects compared to the surrounding areas Said it was still inferior. On the other hand, although the Mianyang government onwards to build a large Jiuzhaigou tourism economic circle since 2014, hoping to create a western tourist gold line, which has the world-famous Jiuzhaigou scenic area as the core.[5] But for now, Beichuan tourism resources have not really integrated into the big Jiuzhaigou tourism gold line, so get the promotion is very limited.

Besides, Beichuan cultural tourism has low level of industrialization and branding. Beichuan cultural tourism can only provide less variety of cultural tourism products, especially the lack of interactive and participatory cultural tourism projects. The ancient Dayu culture, Qiang 
embroidery and Qiang costumes, Qiang folk songs and dance are not integrated to form a brand culture and products, and cultural tourism-related industries and enterprises are also did not form a scale. From the results of the survey is not difficult to see that $69.6 \%$ of visitors mainly want to visit the earthquake site, most of them are the first time come to visit, and visitors in Beichuan's personal consumption is basically less than 200 yuan, including the purchase of souvenirs, specialty products, catering as the main consumer items, $63.5 \%$ of the tourists feel that Beichuan's scenic features are not prominent. 57.4\% of visitors believe that cultural experience not enough depth. In the visitor interview, many tourists said that the actual consumption in Beichuan is lower than their expected consumption, the most obvious is the $18-45$ year old tourists $(77.7 \%$ of the total number of respondents), this part of the young tourists have a strong curiosity, they reflect the new county town was good constructed but the tourism products lack of attractiveness.

In view of this, as soon as possible to complete the integration of Yu Qiang cultural display, to create a unique cultural tourism brand to retain tourists, to promote the development of surrounding industries, are the fundamental develop direction to solve the cultural tourism current problems.

\section{The New Path of Cultural Tourism Development and Its Realization}

The development of cultural tourism in ethnic areas can promote the local economy and conducive to the transmission and dissemination of local culture. Beichuan is the only one Qiang autonomous county in China as well as the birthplace of Dayu, is one of the most important memorial sites of Chinese people seeking roots worship, which has a long history. As some scholars concluded: Beichuan, "there are two extremely important and even monopoly of cultural resources can be developed, that is, Dayu culture and Qiang folk culture.[6] Beichuan Yu-Qiang culture suffered great losses due to the earthquake has been irreversible, the lack of historical relics is also difficult to recover, cultural resources exist short board cannot be ignored. in this condition, Beichuan need to make full use of the advantages of 5A-level scenic resources platform to create a totally new and unique cultural tourism brand, eliminating the homogenization of tourism products of the unfavorable factors for the development of cultural tourism to find a new path.

The most important item of this new path is creativity. For tourists, in the cultural tourism activities to experience and understand the depth of this culture depends on whether they are close enough to this culture, "close" not only refers to the physical space but also in the subjective feelings. We may take the Disneyland as an example, which has always been known for creative design and display. The slogan "Welcome to the Magic" mining the animation culture to the extreme, it's a model of virtual world become real, virtual and real are an organic whole. In fact, Yu-Qiang culture can also learn from it. Beichuan cannot copy the experience of Disney, but can extract the essence of it - "from the virtual to the real, the actual situation combined", make the "virtual" cultural into the reality of the landscape and venues. With the help of high-tech VR (virtual reality) technology, we can achieve the combination of virtual and reality, let the ancient mysterious Yu-Qiang culture presented in front of tourists, and have a deep interaction with visitors.

Virtual Reality (VR) is a kind of computer simulation system which can create and experience virtual world. It uses computer to generate a simulation environment, which is a multi-source information fusion interactive 3D dynamic scene and entity behavior of the simulation system, with the help of helmets, data gloves and other professional equipment, allowing users to enter the virtual space, real-time perception and operation of the virtual world in a variety of objects, so through visual, tactile and auditory access to the real Feelings.[7] Salt Lake City, Utah, has a new high-tech theme park called The Void. In The Void, the entire theme park is made up of gray stone walls, which use virtual reality technology to seamlessly integrate VR images with realistic buildings. Wear an exclusive VR Rapture series helmet, players will immerse in the physical scenes and virtual scenes of the blend, the full feeling 4D effect brought a "real" experience, such as you tapping a slate in the real world, but in the virtual world you're tapping a dashboard, and lamp in the virtual reality is actually only the bubble pillars of the reality and so on. [8] 
Besides, the virtual reality technology can also be applied to the cultural tourism publicity display, cultural heritage restoration and protection, online virtual museum, etc., it can "effectively alleviate contradiction of cultural tourism in the protection and utilization of cultural resources, to provide high-tech support for the cultural tourism business development."[9] In recent years, the VR industry has developed quite rapidly in China, and in the near future VR will change people's way of entertainment. If Beichuan cultural tourism can introduce this technology to built Yu-Qiang cultural experience museum, tourists can wear VR equipment to get into a "real space" of the Qiang people, which is reconstructed by the virtual technology, experience the live space of Qiang people and maybe become one of them. This will be a truly immersive travel experience, tourists can visit the Qiang people's village to see how they live, how to offer sacrifice or get married, and also can join the group of gordro dance, to learn how they blow Qiang flute and to sing the folk songs. In the virtual world without the time, space and weather restrictions, tourists can see and hear and touch all the treasures of Yu-Qiang culture, which may difficult even impossible to experience in the real world. One greater benefits is that the VR Experience Museum not only allows the tourist to experience the same or more profound travel experience in the absence of festivals or folk performances, also does not require tourists to have some cultural knowledge. Even if tourists do not understand the Yu-Qiang cultural can also walk through the museum, little by little feel the spirit of the Qiang people as well as the rich and splendid Yu-Qiang culture. In this way, works of cultural heritage protection can be retained in a more complete and effective way. After all, interaction is more attractive than text description and models, and more conducive to the spread of cultural heritage. Previously the old Beichuan did not have such a condition, whether the land or capital, but now Beichuan not only have flat open terrain and 5A level scenic platform resources, as long as the full use of these resources, can become the basis to achieve a virtual Yu-Qiang culture theme museum (VR Hall). However, the material conditions are important, but more important is the quality of cultural presentation. Beichuan can learn from the "impression - Liu Sanjie" production methods, hire high-level art director, high-tech production team, Yu-Qiang cultural research experts and local Qiang people to participate in. It will become a new and unique brand of Yu-Qiang cultural tourism, thus Beichuan cultural tourism will embark on a new path with its own characteristics and advantages of development.

\section{References}

[1] Ma Ling. Application of Benchmarking Theory in Tourism Research [J]. Journal of Tourism, 2007,22(10):76-81.

[2] Dean MacCannell, Translator:Zhang Xiaoping, etc. New Theory of Leisure Class [M], Guilin: Guangxi Normal University Press, 2008: 101.

[3] Ma Ning. The Authenticity of Tourism Interaction: Hospitality tourism research.[J] Journal of Guangxi University for Nationalities.2007,29(6):18-24.

[4] Beichuan Qiang Autonomous County of Culture, Radio, Film and Television Publishing and Tourism Bureau 2016 work summary and 2017 work plan.[EB/OL] Beichuan government network. 2017-1-5.

http://www.beichuan.gov.cn/content.jsp?id=8a868a3459440e8101596dd2478f0eee\&classid=2e c137984f5d49fab8da7ced61ef10ee

[5] The city and Aba Guangyuan Longnan deep cooperation to build large Jiuzhai tourism economic circle [N]. Mianyang Evening News, 2014-11-21, 2nd edition.

[6] Yi Xiaolong, Chen Qinjian. Study and Countermeasure on the Protection and Development of Yu-Qiang Culture in the Beichuan Qiang Autonomous County after the Earthquake [J].

Northwest Ethnic Studies .2008,4: 1-9. 
[7] The Latest Development and Prospect of Virtual Reality Technology [J]. Chinese Journal of Scientific and Technical Advicament, 2011,20 (1): 1-15.

[8] Corey Protin and Dave Smith: Inside The Void: An exclusive look at the future of virtual reality, TECH INSIDER,2015-9-22.

[9] Li Renren. Application of Virtual Reality Technology in Cultural Heritage Protection [J]. Journal of Yunnan Normal University. 2008,40 (4): 1-7. 